\title{
Assessing the adequacy of lymph node yield for different tumor stages of colon cancer by nodal staging scores
}

\author{
Zhenyu Wu ${ }^{1,2}$, Guoyou Qin ${ }^{1,2}$, Naiqing Zhao ${ }^{1}$, Huixun Jia $^{3}$ and Xueying Zheng ${ }^{1,2^{*}}$
}

\begin{abstract}
Background: According to the current official guidelines, at least 12 lymph nodes (LNs) are qualified as an adequate sampling for colon cancer patients. However, patients evaluated with less nodes were still common in the United States, and the prevalence of positive nodal disease may be under-estimated because of the falsenegative assessment. In this study, we present a statistical model that allows preoperative determination of the minimum number of lymph nodes needed to confirm a node-negative disease with certain confidence.

Methods: Adenocarcinoma colon cancer patients with stage T1-T3, diagnosed between 2004 and 2013, who did not receive neoadjuvant therapies and had at least one lymph node pathologically examined, were extracted from the Surveillance, Epidemiology and End Results (SEER) database. A beta binomial distribution was used to estimate the probability of an occult nodal disease is truly node-negative as a function of total number of LNs examined and T stage.

Results: A total of 125,306 patients met study criteria; and 47,788 of those were node-positive. The probability of falsely identifying a patient as node-negative decreased with an increasing number of nodes examined for each stage, and was estimated to be $72 \%$ for T1 and T2 patients with a single node examined and 57\% for T3 patients with a single node examined. To confirm an occult nodal disease with 90\% confidence, 3, 8, and 24 nodes need to be examined for patients from stage $T 1, T 2$, and $T 3$, respectively.

Conclusions: The false-negative rate of diagnosed node negative, together with the minimum number of examined nodes for adequate staging, depend preoperatively on the clinical $T$ stage. Predictive tools can recommend a threshold on the minimum number of examined nodes regarding to the favored level of confidence for each T stage.
\end{abstract}

Keywords: Colon cancer, False-negative rate, Lymph node, Tumor stage

\section{Background}

Colon cancer is the most common digestive system malignant tumor, accounting for approximately one thirds of the estimated new cases, in the United States in 2016 [1]. Although the incidence rate of colon cancer declines dramatically, decreased by more than $4 \%$ per year in both men and women from 2008 to 2012 [2], it is estimated that 95,270 cases were newly developed in 2016 [1]. Given the fact that about 49,000 Americans died of

\footnotetext{
* Correspondence: xyzheng@fudan.edu.cn

'Department of Biostatistics and Key Laboratory of Public Health Safety,

School of Public Health, Fudan University, Shanghai 200032, China

${ }^{2}$ Collaborative Innovation Center of Social Risks Governance in Health, Fudan

University, 130 Dongan Road, Shanghai 200032, China

Full list of author information is available at the end of the article
}

this disease in 2016 [1], improving the medical and clinical care of colon cancer remains a great challenge. Accurate evaluation of loco-regional lymph nodes (LNs) status is essential for assessing the stage of disease, planning the effective systematic therapies, and predicting the prognosis of these patients [3-8]. Therefore, the detection of positive LNs is critical and a great deal of efforts have been made on determination of the threshold of LNs need to be retrieved. Apparently, if there was too few LNs examined during the surgery, there would be a great chance of being "under-staging" or falsely identifying a node-positive patient as node-negative. Recommendations on lymph node sampling varied from 6 to 21 [9-14], however, most of the studies have 
suggested that an examination of at least 12 regional lymph nodes is reasonable for nodal evaluation for colon cancer patients [15-18]. Official guidelines, such as those announced by the American Joint Committee on Cancer, the American Society of Clinical Oncology, American College of Surgeons, the National Quality Forum, and the National Comprehensive Cancer Network also accepted a minimum of $12 \mathrm{LNs}$ as a standard retrieved from a patient with colon cancer [19-21].

Despite these guidelines, false-negative nodal staging caused by inadequacy of lymph node retrieval exists on a broad scale. Previous studies showed certain interests in developing tools which can help physicians and pathologists predict the probability of missing nodal disease $[12,22]$. In the context of tumor-node-metastasis staging, $\mathrm{T}$ stage was considered as the only stratified covariate in those tools. However, some other key factors, such as therapies and characteristics of patients, were not involved. Patients received neoadjuvant therapy had significantly fewer nodes assessed than patients who underwent surgery alone [23]. The aims of this study were to present a new statistical model to calculate the false-negative probability of occult nodal disease as a function of the number of examined $\mathrm{LNs}$ and the $\mathrm{T}$ stage, using the first primary colon patients without neoadjuvant therapy from a nationwide database. A larger value of the improved nodal staging score (NSS) indicates greater certainty on the node-negative status of a patient.

\section{Methods}

\section{Data source}

Data for the current study were extracted from the Surveillance, Epidemiology, and End Results (SEER)Medicare linked database. The SEER program of National Cancer Institute collects demographics, tumor characteristics, and survival data from 17 population-based cancer registries throughout the United States, covering approximately $28 \%$ of the US population [24]. The SEER-Medicare database has been described in detail elsewhere [25].

\section{Patients}

Only first primary (i.e., only primary cancer or first of two or more primary cancers) colon cancer patients diagnosed between 2004 and 2013 were included. Patients were excluded if they 1) have been treated with neoadjuvant therapy; 2) have histology type other than adenocarcinoma; 3)

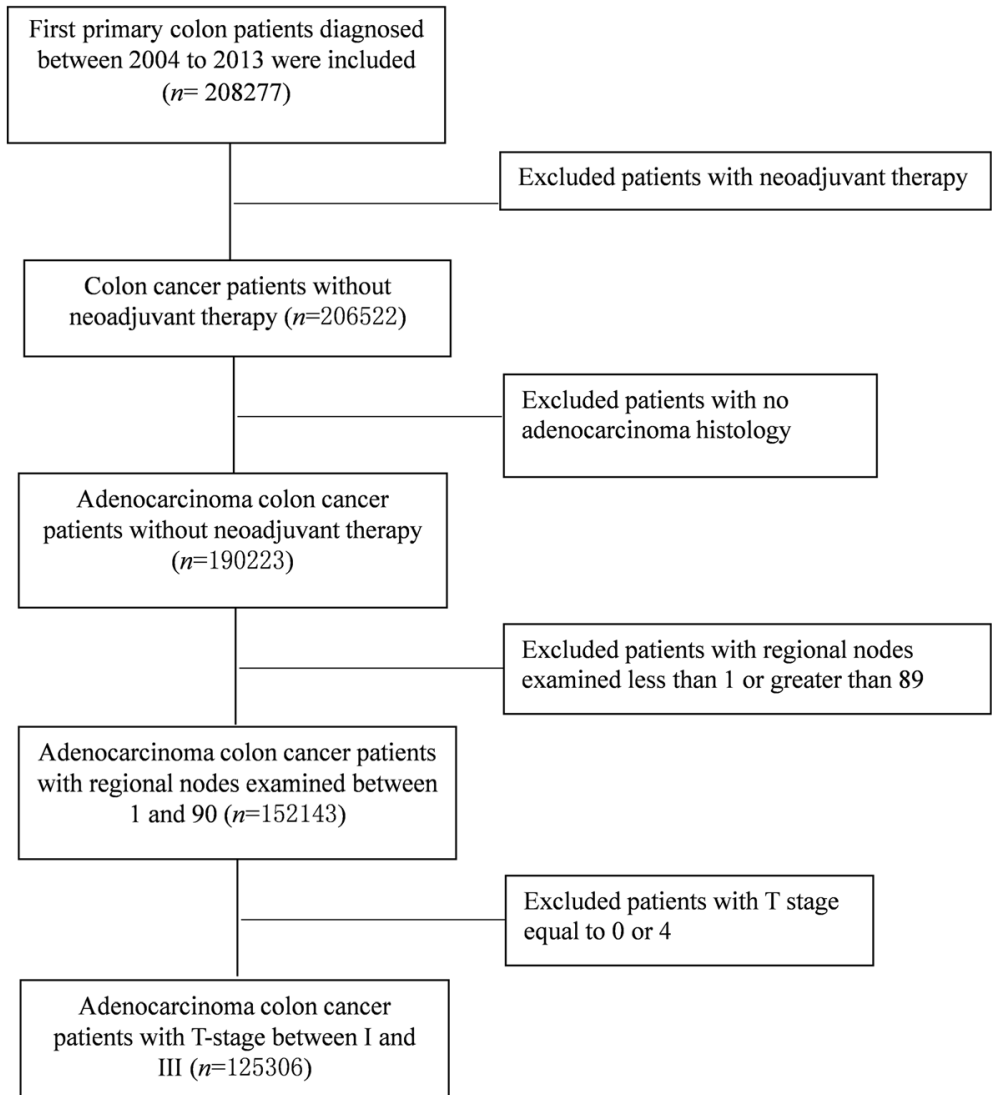

Fig. 1 Flow diagram of colon cancer patients enrolled from the Surveillance, Epidemiology, and End Results (SEER)-Medicare linked database 
have no lymph node examined or the number of lymph nodes examined was not available; 4) T stage equals 0 or 4. A study flowchart is presented in Fig. 1.

\section{Statistical analysis}

The probability that a node-negative patient has nodal disease can be computed using the following algorithm:

1. Compute the probability of missing a positive node as a function of the number of examined nodes, which depends on the number of examined nodes and on $\mathrm{T}$ stage.

2. Compute the corrected prevalence of nodal disease as a function of $\mathrm{T}$ stage, using the probability of missing a positive node.

3. Compute the NSS. This is the probability that a pathologically node-negative patient is actually free of nodal disease, which is calculated from the prevalence and the probability of missing a positive node.

\section{Probability of missing a positive node}

We adapted a beta binomial distribution to estimate the probability of missing a positive node as a function of total number of examined nodes, only using nodepositive patients. Two key assumptions underlie this step: (1) There are no false-positives, and (2) sensitivity is the same for node-positive and node-negative patients. The probability of false-negative depends on the number of examined nodes and on $\mathrm{T}$ stage:

$$
P\left(F N_{m, T}\right)=\frac{\operatorname{Beta}\left(\alpha_{T}, \beta_{T}+m\right)}{\operatorname{Beta}\left(\alpha_{T}, \beta_{T}\right)},
$$

where $m$ denotes the number of nodes examined from 1 to $89, T$ denotes the stage of tumor from T1-T3, and $\operatorname{Beta}()$ represents the beta function. For each tumor stage, $\alpha_{T}$ and $\beta_{T}$ are parameters that characterize the underlying intensity of nodal disease to be estimated from the individual patient data using maximum likelihood approach via VGAM package in $\mathrm{R}$ version 3.2.4.

\section{Estimation of prevalence of nodal disease}

The observed prevalence (OP) is an underestimate and needed to be adjusted for false negatives. This was done in two steps. The first step estimates the number of false negative $\# F N_{m, T}$ as a function of number of examined nodes $(m)$ and stage $(T)$ :

$$
\# F N_{m, T}=\frac{P\left(F N_{m, T}\right)^{*}\left(T P_{m, T}\right)}{1-P\left(F N_{m, T}\right)},
$$

where $\# T P_{m, T}$ is the number of true positives for a given number of examined nodes $(m)$ and stage $(T)$. The second step obtains the corrected prevalence (CP) for each stage by summing over all the number of examined nodes $(m)$ :

$$
\begin{aligned}
C P_{T} & =\frac{\sum_{m}\left(\# T P_{m, T}+\# F N_{m, T}\right)}{\sum_{m}\left(\# T P_{m, T}+\# T N_{m, T}+\# F N_{m, T}\right)} \\
& =\frac{\sum_{m}\left(\# T P_{m, T}+\# F N_{m, T}\right)}{\text { All Patients }} .
\end{aligned}
$$

\section{Nodal staging score}

We assessed adequate staging by computing the NSS, the probability that a pathologically $\mathrm{LN}$-negative patient is indeed free of nodal metastasis:

$$
N S S_{m, T}=\frac{1-C P_{T}}{1-C P_{T}+C P_{T}^{*} P\left(F N_{m, T}\right)} .
$$

\section{Confidence intervals}

Precision of the reported estimates was assessed by creating 1000 bootstrap samples from the entire data set and replicating the estimation process. The 2.5th and 97.5th percentiles were used as the lower and upper 95\% confidence intervals for the corresponding estimates, respectively.

\section{Results}

A total of 125,306 qualified patients were involved in our analyses. The proportions of patients with stage $\mathrm{T} 1, \mathrm{~T} 2$ and T3 primary tumor were $14.51 \%, 17.04 \%$ and $68.45 \%$, respectively. The median number of LNs was gradually increased with $\mathrm{T}$ stage, from 13 to 16 . In addition, the proportion of $\geq 12$ LNs examined and the rate of node-positivity were compared. Most of the enrolled patients were examined with more than 12 nodes, however, the highest node-positive rate was observed in patients with T3 stage. As expected, the rate of patients with positive node was lowest in T1 stage (11.12\%) and highest in T3 stage (48.54\%). The detailed summaries of patients and LNs were shown in Table 1.

The distribution of the percentage of positive metastatic LNs among all patients with at least one positive node ( $n=47,788)$ was fit using a beta-binomial distribution with resulting model parameter estimates of $\alpha=1.130$

Table 1 Descriptions of enrolled patients and lymph nodes examined

\begin{tabular}{lllll}
\hline T stage & $N(\%)$ & $\operatorname{LNE}(M)$ & $\begin{array}{l}\text { Rate of } \geq 12 \\
\operatorname{LNE}(\%)\end{array}$ & $\begin{array}{l}\text { Proportion of } \\
\text { node-positivity (\%) }\end{array}$ \\
\hline T1 & $18,181(14.51)$ & 13 & 60.26 & 11.12 \\
T2 & $21,355(17.04)$ & 15 & 72.55 & 19.35 \\
T3 & $85,770(68.45)$ & 16 & 77.92 & 48.54
\end{tabular}

LNE lymph nodes examined, $M$ median 
Table 2 Estimated parameters across different stages

\begin{tabular}{llll}
\hline Parameter & All & T1 and T2 & T3 \\
\hline$a_{T}$ & 1.130 & 1.960 & 1.117 \\
$\beta_{T}$ & 3.201 & 10.453 & 2.957 \\
\hline
\end{tabular}

(95\% CI, 1.111 to 1.149 ) and $\beta=3.201$ (95\% CI, 3.128 to 3.288) (Table 2). Stratified by tumor stages ( $\mathrm{T}$ stage), the resulting parameters were $\alpha_{1}=\alpha_{2}=1.960$ (95\% CI, 1.813 to 2.119) and $\beta_{1}=\beta_{2}=10.453$ (95\% CI, 9.335 to 11.549 ) for stages T1 and T2 (estimated by $n=6153$ patients in stage $\mathrm{T} 1$ and T2 with at least one positive node). For stage T3, $\alpha_{3}=1.117$ (95\% CI, 1.100 to 1.136 ) and $\beta_{3}=2.957$ (95\% CI, 2.886 to 3.046$)$ were estimated by all the patients in stage T3 with at least one positive node $(n=41,635)$.

The set of parameters was then used to estimate the probability of false-negative disease as a function of the number of examined nodes and tumor stages, which is different from studies of Joseph et al. [13] and Gönen et al. [12]. In stages $\mathrm{T} 1$ and $\mathrm{T} 2$, the probability of a false-negative node dissection was estimated at $72 \%, 54 \%, 26 \%, 12 \%$ and less than $10 \%$ for $1,3,10,20$ and greater than 26 nodes examined, respectively (Fig. 2 and Additional file 1: Table S1 in the supporting information). In stage T3, the probability of a false-negative node dissection was estimated at $57 \%, 39 \%, 18 \%$ and less than $10 \%$ for 1,3 , 10 and greater than 20 nodes examined, respectively. It is shown in Fig. 2 that the overall $\alpha$ and $\beta$ were prone to underestimate the probability of falsenegative in stages $\mathrm{T} 1$ and $\mathrm{T} 2$ and overestimate the probability of stage T3. The differences among probability of false-negative in three stages are less than $3 \%$ when more than 20 nodes are examined.
The observed prevalence of nodal disease is $38.1 \%$, but accounting for false-negative patients, the corrected prevalence is $45.4 \%$ (Table 3 ). Underestimation of prevalence due to the existence of false- negatives is observed for all $\mathrm{T}$ stages, but its extent increases by $\mathrm{T}$ stage. As many as $57.0 \%$ of $\mathrm{T} 3$ colon cancer patients are estimated to have nodal disease, up from an observed rate of $48.5 \%$.

Nodal staging scores were presented in Fig. 3 and Additional file 1: Table S2 in the supporting information. Patients with stage T1 and T2 will have more than a $90 \%$ chance of a correct pathologic diagnosis with three and eight examined nodes, respectively. The same level of accuracy requires twenty-four examined nodes in T3 patients. To achieve an $80 \%$ chance of a correct pathologic diagnosis, one, one and ten nodes are required to be examined for T1, T2 and T3 patients, respectively.

\section{Discussion}

Adequate examined nodes are required for proper staging of colon cancer, and the number of LNs examined is associated with colon cancer survival [15]. When patients have too few nodes examined, clinicians face challenging decisions on under-staging because there would be a chance that this patient can be incorrectly treated as false-negative. By maximizing the prognostic discrimination between the grouped patients, many studies have sought a threshold for the minimum number of examined nodes [26-29], in which most of these suggestions have been made with regard to the number of examined nodes needed to accurately determine that a patient has occult node-negative cancer.

Recent studies subjected nodal staging to the statistical model by computing the false-negative rate and calculating

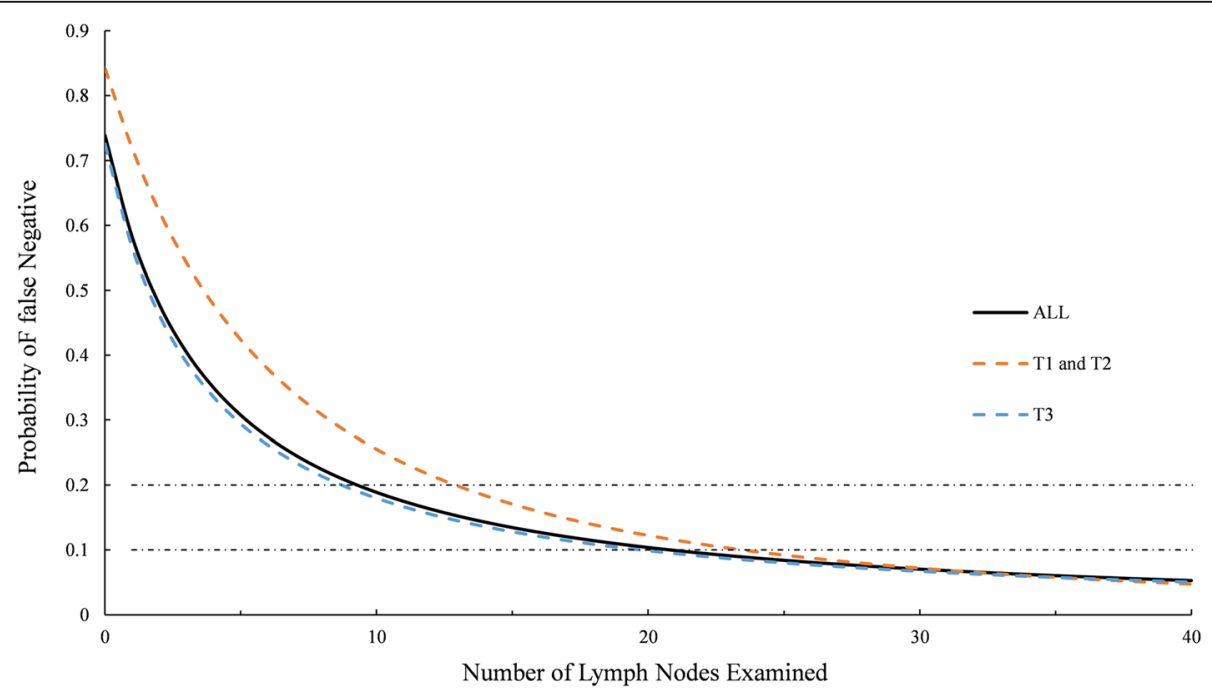

Fig. 2 Probability of a false-negative as a function of number of nodes examined in a colon cancer patient with truly node-positive disease 
Table 3 Observed and Corrected Prevalence

\begin{tabular}{lllll}
\hline Prevalence(\%) & All & T1 & T2 & T3 \\
\hline OP & 38.1 & 11.1 & 19.3 & 48.5 \\
CP & 45.4 & 15.3 & 25.0 & 57.0 \\
\hline
\end{tabular}

the negative predictive value to define NSS that characterizes the adequacy of node-negative classification $[12,22,30$, 31]. However, most of these studies lose sight of the effect of tumor stage on the false-positive rate in the surgery of colon cancer. To the best of our knowledge, this study is the first to formulate the false-positive rate of occult nodal disease as a function of the number of examined nodes together with the $\mathrm{T}$ stage, and find a significant difference of false-positive rate among different $\mathrm{T}$ stages. Combining the number of examined nodes with the $\mathrm{T}$ stage, our approach established an individualized prognostication of the true nodal stage. Our results suggested an evident higher falsepositive rate of $\mathrm{T} 1$ and $\mathrm{T} 2$ patients comparing to that of $\mathrm{T} 3$ patients when the number of examined nodes is less than 15 , and a small but statistically significant higher falsepositive rate of $3 \%$ when the number of examined nodes is between 15 and 20 .

In addition, in order to minimize the bias caused by important confounders, we restricted our study population to first primary colon patients without neoadjuvent therapies. To facilitate the planning of the optimal individual treatment, we also evaluated whether other patient variables, such as patient sex and age, could lead to different false-positive rates. However, current data do not support that either patient sex or age can result in significantly different false-positive rates. Although we found that not all clinicopathological features are highly correlated with the false-positive rate in colon cancer, whether these features influence the false-positive rates in other categories of cancer are still open questions.

As a convenient tool to evaluate whether a nodenegative colon cancer patient is adequately staged, a higher value of the calculated NSS implies a greater likelihood in the node-negative status of the patient for each tumor stage. Because the NSS calculates the probability of occult nodal disease as a function of the number of examined nodes and the $\mathrm{T}$ stage, this tool might give an estimation of the likelihood of node-metastasis more accurately than a simple cutoff of the number of examined nodes, and help clinicians judge the adequacy of nodal staging. Current guidelines recommended that at least 12 nodes needed to be examined as a quality indicator, based on a series of studies correlating the number of examined LNs with progression or survival [15-17]. However, we found that the number of nodes needed to be removed varies largely among patients according to different $\mathrm{T}$ stages [32]. For example, insisting on 12 nodes for patients with stages $\mathrm{T} 1$ and $\mathrm{T} 2$ seems unjustified, because the examination of 3 nodes for a T1 patient maintains the same level of confidence $90 \%$ with that of the examination of 8 nodes for a T2 patient. Consequently, our findings encourage the development of techniques to improve LNs harvest in color cancer especially for T3 patients.

Given the retrospective nature and a few key assumptions required for the calculation of NSS, there are several limitations of this study that warrant mention. First, although the assumptions on no false-positives and betabinomial model are conservative and reasonable [12], the assumption that all nodes within a patient have the

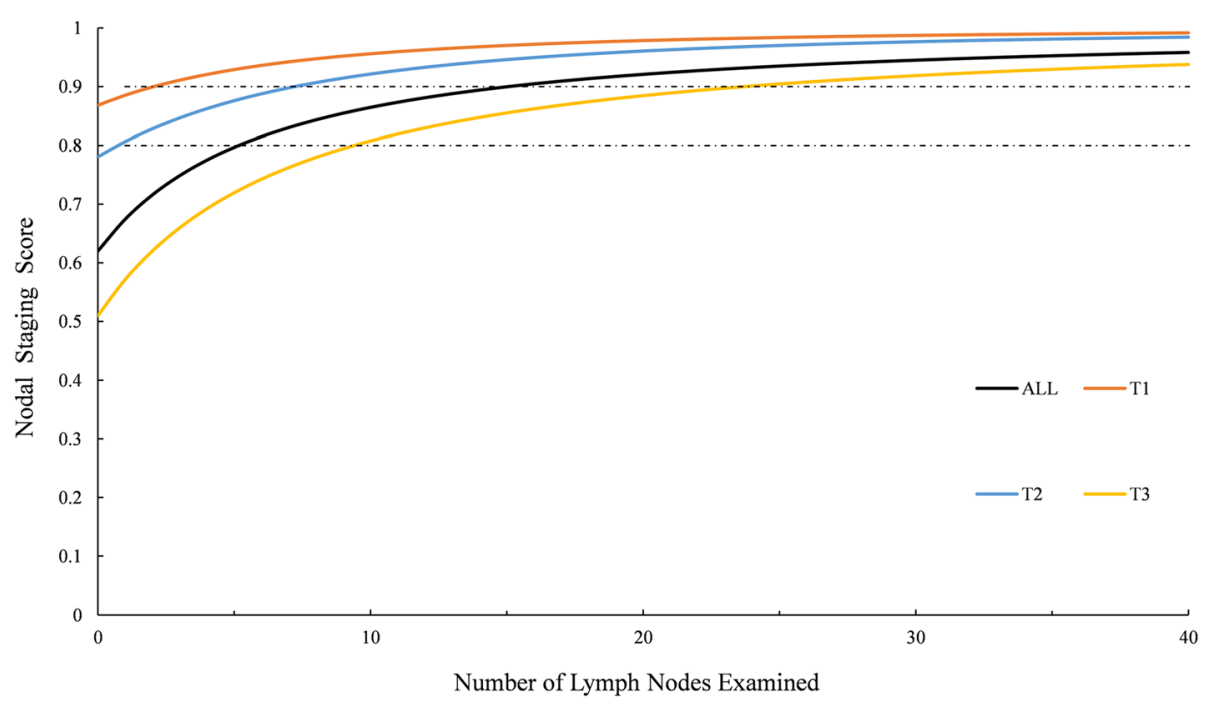

Fig. 3 Nodal staging scores as a function of number of nodes examined in a colon cancer patient 
same probability of being involved is unlikely to hold in practice. We recognize, however, that the absence of the position of the examined nodes limit the justification on this assumption. The location of the examined nodes is substantial because nodes from an area of low likelihood of cancer may be less valuable than the nodes which are more likely to be involved with malignancy [31]. Consequently, prospective validation on this key assumption is required in the statistical model to estimate NSS in future. Secondly, the data from nodes-positive patients were used to interpret the data for the nodes-negative patients. We applied a bootstrap method to generate nodes-negative patients from observed nodes-positive patients by reducing one node that with equal possibility to be selected. The estimates of the false-positive rate from the bootstrap samples are in line with the estimates obtained only from nodes-positive patients, which justifies the rationality of the extension. Finally, as mentioned by many studies, the externally validation of the use of the NSS relies on the result of recurrence or death, to ensure that NSS can distinguish patients who are at high risk of having omitted occult nodal disease [12].

In conclusion, our study has several key distinctions. Strengths of our analysis included its novel application of tumor-stage-based false-positive rates into the calculation of NSS. The formula of prevalence and NSS varies in a way from the equations described in previous research. Our results allow clinicians to better understand the likelihood of missing nodal disease and assist the planning of optimal therapies.

\section{Conclusions}

In conclusion, this study found that the false-negative rate of the examined lymph nodes in the colon cancer surgery depends preoperatively on the clinical $\mathrm{T}$ stage. A more accurate nodal staging score was developed to recommend a threshold on the minimum number of examined nodes regarding to the favored level of confidence for each T stage.

\section{Additional file}

Additional file 1: Table S1. Probability of missing nodal disease (false negative, \%) for selected values of the number of nodes examined. Table S2. Nodal staging score for selected values of the number of nodes examined. (DOCX $54 \mathrm{~kb}$ )

\section{Abbreviations}

CP: corrected prevalence; LN: lymph node; NSS: nodal staging score; OP: observed prevalence; SEER: surveillance, epidemiology and end results

\section{Acknowledgements}

The authors acknowledge the efforts of the Surveillance, Epidemiology, and End Results (SEER) Program tumor registries in the creation of the SEER database.
Consent to publication

Not applicable.

\section{Funding}

This study was supported by the National Science Foundation of China (No. $11371100 ; 11,501,124)$. The funders had no role in the study design, data collection and analysis, decision to publish, or preparation of the manuscript.

\section{Availability of data and materials}

Any request of data and material may be sent to the corresponding author.

\section{Authors' contributions}

All authors made substantial contributions to one or more of the following: the study conception and design (ZW, XZ); acquisition of data or analysis (ZW, GQ, NZ, HJ); and interpretation of data (ZW, GQ, NZ, HJ, XZ). ZW and XZ drafted the article and all other authors contributed to revising the article critically for important intellectual content. All authors read and approved the final manuscript.

\section{Ethics approval and consent to participate}

This study was partly based on the publicly available SEER database and we have got the permission to access the database on purpose of research only (Reference number: 14,120-Nov2015). It did not include interaction with humans or use personal identifying information. The informed consent was not required for this research.

\section{Competing interests}

The authors declare that they have no competing interests.

\section{Publisher's Note}

Springer Nature remains neutral with regard to jurisdictional claims in published maps and institutional affiliations.

\section{Author details}

'Department of Biostatistics and Key Laboratory of Public Health Safety, School of Public Health, Fudan University, Shanghai 200032, China. ${ }^{2}$ Collaborative Innovation Center of Social Risks Governance in Health, Fudan University, 130 Dongan Road, Shanghai 200032, China. ${ }^{3}$ Center for Biomedical Statistics, Fudan University Shanghai Cancer Center, Shanghai 200032, China.

Received: 16 March 2017 Accepted: 19 July 2017

Published online: 25 July 2017

\section{References}

1. American Cancer Society. Cancer Facts \& Figures 2016. Atlanta: American Cancer Society; 2016.

2. American Cancer Society. Colorectal Cancer Facts \& Figures 2014-2016. Atlanta: American Cancer Society; 2014.

3. Akagi Y, Adachi Y, Kinugasa T, Oka Y, Mizobe T, Shirouzu K. Lymph node evaluation and survival in colorectal cancer: review of population-based, prospective studies. Anticancer Res. 2013;33(7):2839-47.

4. Chang GJ, Rodriguez-Bigas MA, Skibber JM, Moyer VA. Lymph node evaluation and survival after curative resection of colon cancer: systematic review. J Natl Cancer Inst. 2007:99(6):433-41.

5. Berger AC, Sigurdson ER, LeVoyer T, Hanlon A, Mayer RJ, Macdonald JS, Catalano PJ, Haller DG. Colon Cancer survival is associated with decreasing ratio of metastatic to examined lymph nodes. J Clin Oncol. 2005;23(34):8706-12.

6. Markl B. Stage migration vs immunology: the lymph node count story in colon cancer. World J Gastroenterol. 2015;21(43):12218-33.

7. Hogan NM, Winter DC. A nodal positivity constant: new perspectives in lymph node evaluation and colorectal cancer. World J Surg. 2013;37(4):878-82.

8. Costi R, Beggi F, Reggiani V, Ricco M, Crafa P, Bersanelli M, Tartamella F, Violi V, Roncoroni L, Sarli L. Lymph node ratio improves TNM and AstlerColler's assessment of colorectal cancer prognosis: an analysis of 761 node positive cases. J Gastroimtest Surg. 2014;18(10):1824-36.

9. Shanmugam C, Hines RB, Jhala NC, Katkoori VR, Zhang B, Posey JJ, Bumpers HL, Grizzle WE, Eltoum IE, Siegal GP, Manne U. Evaluation of lymph node numbers for adequate staging of Stage II and III colon cancer. J Hematol Oncol. 2011;4:25. 
10. Vather R, Sammour T, Kahokehr A, Connolly AB, Hill AG. Lymph node evaluation and long-term survival in stage II and stage III colon cancer: a national study. Ann Surg Oncol. 2009;16(3):585-93.

11. Wong JH, Severino R, Honnebier MB, Tom P, Namiki TS. Number of nodes examined and staging accuracy in colorectal carcinoma. J Clin Oncol. 1999:17(9):2896-900.

12. Gonen M, Schrag D, Weiser MR. Nodal staging score: a tool to assess adequate staging of node-negative colon cancer. J Clin Oncol. 2009;27(36):6166-71.

13. Joseph NE, Sigurdson ER, Hanlon AL, Wang H, Mayer RJ, MacDonald JS, Catalano PJ, Haller DG. Accuracy of determining nodal negativity in colorectal cancer on the basis of the number of nodes retrieved on resection. Ann Surg Oncol. 2003;10(3):213-8.

14. lachetta F, Reggiani BL, Marcheselli L, Di Gregorio C, Cirilli C, Messinese S, Cervo GL, Postiglione R, Di Emidio K, Pedroni M, Longinotti E, Federico M, Ponz de Leon M. Lymph node evaluation in stage IIA colorectal cancer and its impact on patient prognosis: a population-based study. Acta Oncol. 2013:52(8):1682-90.

15. Baxter NN, Virnig DJ, Rothenberger DA, Morris AM, Jessurun J, Virnig BA. Lymph node evaluation in colorectal cancer patients: a population-based study. J Natl Cancer Inst. 2005;97(3):219-25.

16. Shia J, Wang H, Nash GM, Klimstra DS. Lymph node staging in colorectal cancer: revisiting the benchmark of at least 12 lymph nodes in R0 resection. J Am Coll Surg. 2012;214(3):348-55.

17. Chen HH, Chakravarty KD, Wang JY, Changchien CR, Tang R. Pathological examination of 12 regional lymph nodes and long-term survival in stages I-III colon cancer patients: an analysis of 2,056 consecutive patients in NE.Reftwo branches of same institution. Int J Color Dis. 2010;25(11):1333-41.

18. Tsai HL, Huang CW, Yeh YS, Ma CJ, Chen CW, Lu CY, Huang MY, Yang IP, Wang JY. Factors affecting number of lymph nodes harvested and the impact of examining a minimum of 12 lymph nodes in stage I-III colorectal cancer patients: a retrospective single institution cohort study of 1167 consecutive patients. BMC Surg. 2016;16:17.

19. American Joint Committee on Cancer. Cancer staging manual. 5th ed. Chicago, IL: Springer; 1997.

20. Bilimoria KY, Bentrem DJ, Stewart AK, Talamonti MS, Winchester DP, Russell TR, Ko CY. Lymph node evaluation as a colon cancer quality measure: a national hospital report card. J Natl Cancer Inst. 2008;100(18):1310-7.

21. Nelson H, Petrelli N, Carlin A, Couture J, Fleshman J, Guillem J, Miedema B, Ota D, Sargent D. Guidelines 2000 for colon and rectal cancer surgery. J Natl Cancer Inst. 2001;93(8):583-96.

22. Robinson TJ, Thomas S, Dinan MA, Roman S, Sosa JA, Hyslop T. How many lymph nodes are enough? Assessing the adequacy of lymph node yield for papillary thyroid cancer. J Clin Oncol. 2016;34(28):3434-9.

23. Govindarajan A, Gonen M, Weiser MR, Shia J, Temple LK, Guillem JG, Paty PB, Nash GM. Challenging the feasibility and clinical significance of current guidelines on lymph node examination in rectal cancer in the era of neoadjuvant therapy. J Clin Oncol. 2011;29(34):4568-73.

24. National Cancer Institute. About the SEER program. http://seer.cancer.gov/ about/. Accessed 28 Feb 2017.

25. Warren JL, Klabunde CN, Schrag D, Bach PB, Riley GF. Overview of the SEERMedicare data: content, research applications, and generalizability to the United States elderly population. Med Care. 2002;40(8 Suppl):IV-3-18.

26. Jessup JM, McGinnis LS, Steele GJ, Menck HR, Winchester DP. The National Cancer Data Base. Report on colon cancer. Cancer. 1996;78(4):918-26.

27. Goldstein NS. Lymph node recovery from colorectal resection specimens. Dis Colon rectum. 1999;42(8):1107-8.

28. Le Voyer TE, Sigurdson ER, Hanlon AL, Mayer RJ, Macdonald JS, Catalano PJ, Haller DG. Colon Cancer survival is associated with increasing number of lymph nodes analyzed: a secondary survey of intergroup trial INT-0089. J Clin Oncol. 2003;21(15):2912-9.

29. Chen SL, Bilchik AJ. More extensive nodal dissection improves survival for stages I to III of colon cancer: a population-based study. Ann Surg. 2006;244(4):602-10.

30. Kluth LA, Abdollah F, Xylinas E, Rieken M, Fajkovic H, Seitz C, Sun M, Karakiewicz PI, Schramek P, Herman MP, et al. Clinical nodal staging scores for prostate cancer: a proposal for preoperative risk assessment. $\mathrm{Br}$ J Cancer. 2014;111(2):213-9.

31. Shariat SF, Ehdaie B, Rink M, Cha EK, Svatek RS, Chromecki TF, Fajkovic H, Novara G, David SG, Daneshmand S, et al. Clinical nodal staging scores for bladder cancer: a proposal for preoperative risk assessment. Eur Urol. 2012;61(2):237-42.

32. Markl B, Olbrich $G$, Schenkirsch $G$, Kretsinger $H$, Kriening B, Anthuber M. Clinical significance of international union against cancer pN staging and lymph node ratio in node-positive colorectal cancer after advanced lymph node dissection. Dis Colon rectum. 2016:59(5):386-95.

\section{Submit your next manuscript to BioMed Central and we will help you at every step:}

- We accept pre-submission inquiries

- Our selector tool helps you to find the most relevant journal

- We provide round the clock customer support

- Convenient online submission

- Thorough peer review

- Inclusion in PubMed and all major indexing services

- Maximum visibility for your research

Submit your manuscript at www.biomedcentral.com/submit
Biomed Central 